\title{
GREEN AND BLUE INFRASTRUCTURE TO REGULATE THERMAL COMFORT IN HIGH DENSITY CITY PLANNING- A CASE OF NAVI MUMBAI, INDIA
}

ADINARAYANANE RAMAMURTHY, Associate Professor and Head- Department of Planning, School of Planning and Architecture Vijayawada, Andhra Pradesh; India

ANUSHA ROY, Master in Environmental Planning and Management- Department of Planning, School of Planning and Architecture Vijayawada, Andhra Pradesh; India

\begin{abstract}
Cities create an environment that is clearly distinct from their surrounding areas. Urban structures alter the surface energy budget, modify the vertical profile of various atmospheric properties, interact with both local and regional circulation, and introduce anthropogenic heat. As a result, the climate conditions in the urban environment significantly differ from their rural system. Sustainability in planning is a topic of high interest among urban planners, urbanist and policy makers yet lack of scientific knowledge in the field leads to low impact in evolving urban planning decisions. Urban climatic map, as a tool provides a visual and spatial information platform using Geographic Information System (GIS). Increase in vegetation and water surfaces, known as green and blue infrastructure (GBI), is of particular interest due to their multiple functionality and benefits for the urban environment, such as increasing urban biodiversity and improving air quality in case of urban vegetation.

The urban climatic, environmental and planning parameters, as well as their impact, are considered to synthesize and comprehensively evaluate the physical urban environment with regard to thermal load and dynamic potential. The parameters considered to evaluate Thermal load include: Topography; Population Density; Land Surface Temperature; Air Temperature and Dynamic potential are: Normalized difference Built up Index; Normalized difference Vegetation Index; Normalized difference Water Index and Prevailing Wind of the study region. Study concludes with planning decisions to develop urban climatology-based map for GBI to enhance cooling effects and thereby undertaking measures to regulate thermal comfort in the city through green and blue infrastructure.
\end{abstract}

\section{Keywords}

Urbanization; GBI; Thermal load; Dynamic Potential; Urban Climatic Map; Sustainable Built Environment

\section{Introduction}

\subsection{Background}

World has seen an increased gathering of its population in urban areas, since 1990. This trend is not new, but relentless and has been marked by a remarkable increase in the 
absolute numbers of urban dwellers from a yearly average of 57 million, between 1990-2000 to 82 million by 2018. In 1990, 43 per cent ( 2.3 billion) of the world's population lived in urban areas; by 2015, this had grown to 54 per cent (4 billion) (UN Habitat, 2016). By 2050, global population is projected to increase to around 9.8 billion. It's estimated that more than twice as many people in the world will be living in urban (6.7 billion) than in rural settings (3.1 billion). It's projected that 68 percent of the world's population will live in urban areas (Roser, 2018).

Such urban expansion is not only wasteful in terms of land and energy consumption, but increases greenhouse gas emissions. It has also led to the alteration of ecological systems in many cities over the past two decades (UN Habitat, 2016). Urbanization directly contributes to deforestation of large chunks of tree cover for accommodating the ever-increasing population. This leads to decrease in the services provided by the natural system. Urban structures alter the surface energy budget, modify the vertical profile of various atmospheric properties, interact with both local and regional circulation, and introduce additional sources of heat (e.g. anthropogenic heat). As a result, the climate conditions in the urban environment significantly differ from their rural counterparts (Di Luca, 2015).

In view of above it is inevitable to have a sustainable planning strategy for high density cities. Sustainability in planning is a topic of high interest among planners yet lack of scientific knowledge in the field leads to low impact urban planning decisions. Urban climatic map (UC map) as a tool provides the visual and spatial information platform using GIS (Ar. Ebin Horrison, 2011). Increase in vegetation and water surfaces, known as green and blue infrastructure, is of particular interest due to their multiple functionality and benefits for the urban environment, such as increasing urban biodiversity and improving air quality in case of urban vegetation (Früh, 2016).

\subsection{Research Concern}

The high-density cities contribute by various factors in increasing the thermal stress in the city. For a sustainable built environment, it is important for planners to strategize the city planning to achieve thermal comfort. At the same time, climatic conditions at city level have to be collaborated with plan making. Climatic concerns in urban planning and design can impact on the thermal performance of urban areas, help reduce energy consumption and dependency on fossil fuels, decrease emissions, provide energy and cost efficiency, and contribute to cleaner and more comfortable environments(GEDiKLi, 2018). This research is an attempt to understand how urban climate maps can be operational to arrive at plausible decisions in urban planning, thereby undertaking measures to regulate thermal comfort in the city through green and blue infrastructure.

Keeping the aforesaid knowledge in mind, the researchers have chosen Navi Mumbai as study area for further investigation.

\section{Urban Climate Dynamics}

\subsection{Urban Climate Dynamics}

There is a general understanding that - "A different climate is produced by the built environment in urban areas - the urban climate". Today, the term "urban climate" also encompasses the change in the natural composition of the air through anthropological 
influences. Every structure has an influence upon the individual climatic elements. Large built-up areas divorce themselves in a climatic sense from their surrounding landscape. The significant causes contributing to the production of a separate urban climate lie in the farreaching alteration of the heat budget and the local wind field. This heat can be either stored or emitted from any urban area from the building volume, topography, population density and land uses. The intra-urban air temperature variations due to the urban forms and surfaces can be termed as Thermal Load. A key problem of urbanization is the Thermal Load it generates due to buildings and artificial/man made surfaces (ARUP, 2006). This thermal load can be minimized with the availability of wind and cold air mass exchange in particular localities of urban areas. The availability of green and blue spaces in any city can catalyse the cooling effect which can thereby reduce the thermal load of the city (K.R. Gunawardena, 2016).

\subsection{Physical Criterion for Developing Urban Climatic Map}

The urban climate of the city can be characterized with a balanced consideration of -negative effects, i.e. the Thermal Load (e.g. building bulks) and - positive effects, i.e. mitigation factors to reduce Thermal Load (e.g. green spaces) and promote Dynamic Potential (e.g. air ventilation). Table 1 depicts the all the input layers required to generate the Therma Load and Dynamic Potential of the study area.

Table No. 1 Overview of GIS layers for Urban Climate Analysis Map

\begin{tabular}{|c|c|c|c|}
\hline S.No & $\begin{array}{l}\text { PHYSICAL } \\
\text { CRITERION }\end{array}$ & $\begin{array}{c}\text { EFFECT ON } \\
\text { TEMPERATURE }\end{array}$ & INPUT LAYERS \\
\hline 1 & Thermal Load & Positive & $\begin{array}{l}\text { 1. Topography } \\
\text { 2. Population Density } \\
\text { 3. Land Surface Temperature } \\
\text { 4. Air Temperature } \\
\text { 5. Normalized difference Built up } \\
\text { Index (NDBI) }\end{array}$ \\
\hline 2 & $\begin{array}{l}\text { Dynamic } \\
\text { Potential }\end{array}$ & Negative & $\begin{array}{l}\text { 1. Normalized difference Vegetation } \\
\text { Index (NDVI) } \\
\text { 2. Normalized difference Water Index } \\
\text { (NDWI) } \\
\text { 3. Prevailing Wind }\end{array}$ \\
\hline
\end{tabular}

Source: Compiled by the researcher based on literature review, 2019.

\subsection{Thermal Load Map}

By adding the specific classification values of the above 6 layers based on weightages given to each parameter determined by the regression and correlations with respect to Land Surface Temperature (Topography, Population Density, Land Surface Temperature, Air Temperature, Normalized difference Built up Index (NDBI)). The classification values for the composite layer of Thermal Load are derived and the result generated is presented in figure 1, which indicates the rank wise temperature values in the system. The Higher ranks shows areas with low temperature.

It has been observed that darker shades of red and orange shows the higher intensity of thermal load in certain location of the study area. It can be clearly seen how the areas near to the water body and green spaces are relatively having lesser thermal load compared to 
the other areas. Further, Figure 1 reveals that areas with higher built up show shades of darker yellow and orange which is comparatively warmer.
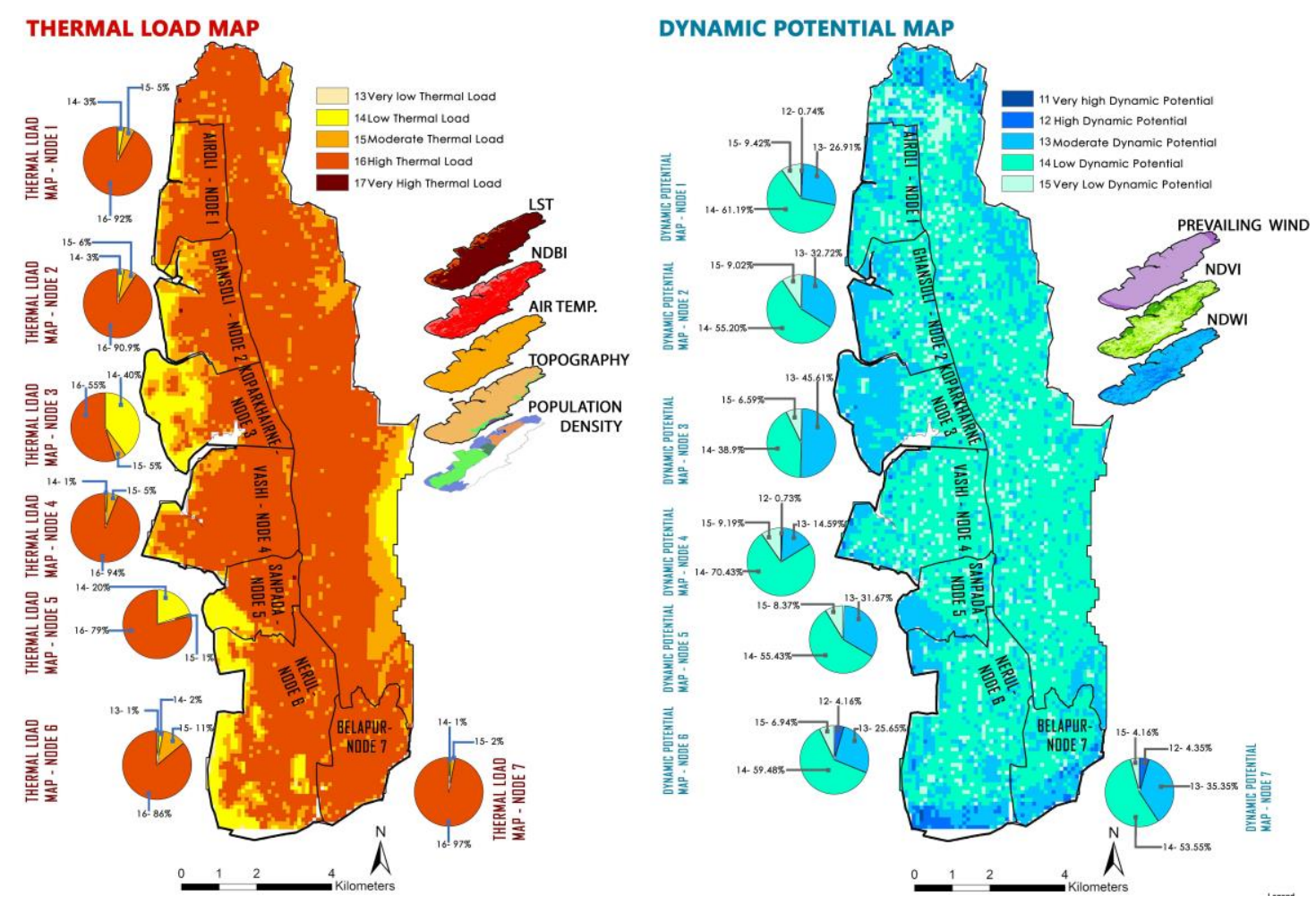

Figure 1 Thermal Load and Dynamic Potential Map for Navi Mumbai, 2018

Source: Map generated by the researcher based on the thermal load and dynamic potential parameters, 2019

\subsection{Dynamic Potential Map}

The parameters which are in negative correlation with temperature, which can better mitigate the heat load of the city are added together based on the weightages depending on the correlations and regressions to prepare the dynamic potential of the city and results were generated through map and presented in Figure 1, which indicates the rank wise temperature values in the system. The higher ranks indicate low temperature values in the system.

It has been observed that the areas near to the Creek and ponds are comparatively cooler than the inner city. Areas with decreasing cooling effect can be attributed to the lesser extend of Green and Blue infrastructure in those areas. The northern and the southern part experiences much cooler temperature which can be due to creeks on South and North as well prevailing winds which have more velocity, in the study region.

\subsection{Urban Climate Analysis Map}

The thermal load and dynamic potential values are synergised through the function of raster calculation in GIS to generate the Urban Climate Analysis map (Shown in Figure 3 - left). This results in 9 classes, however, for the purpose of planning information needs, the 9 classes are simplified and collated into 4 classifications as shown is Figure 3 (right). This map acts as 
an information and evaluation tool which integrates the climate and planning factors and guides the planners by providing an urban climate-based planning network.
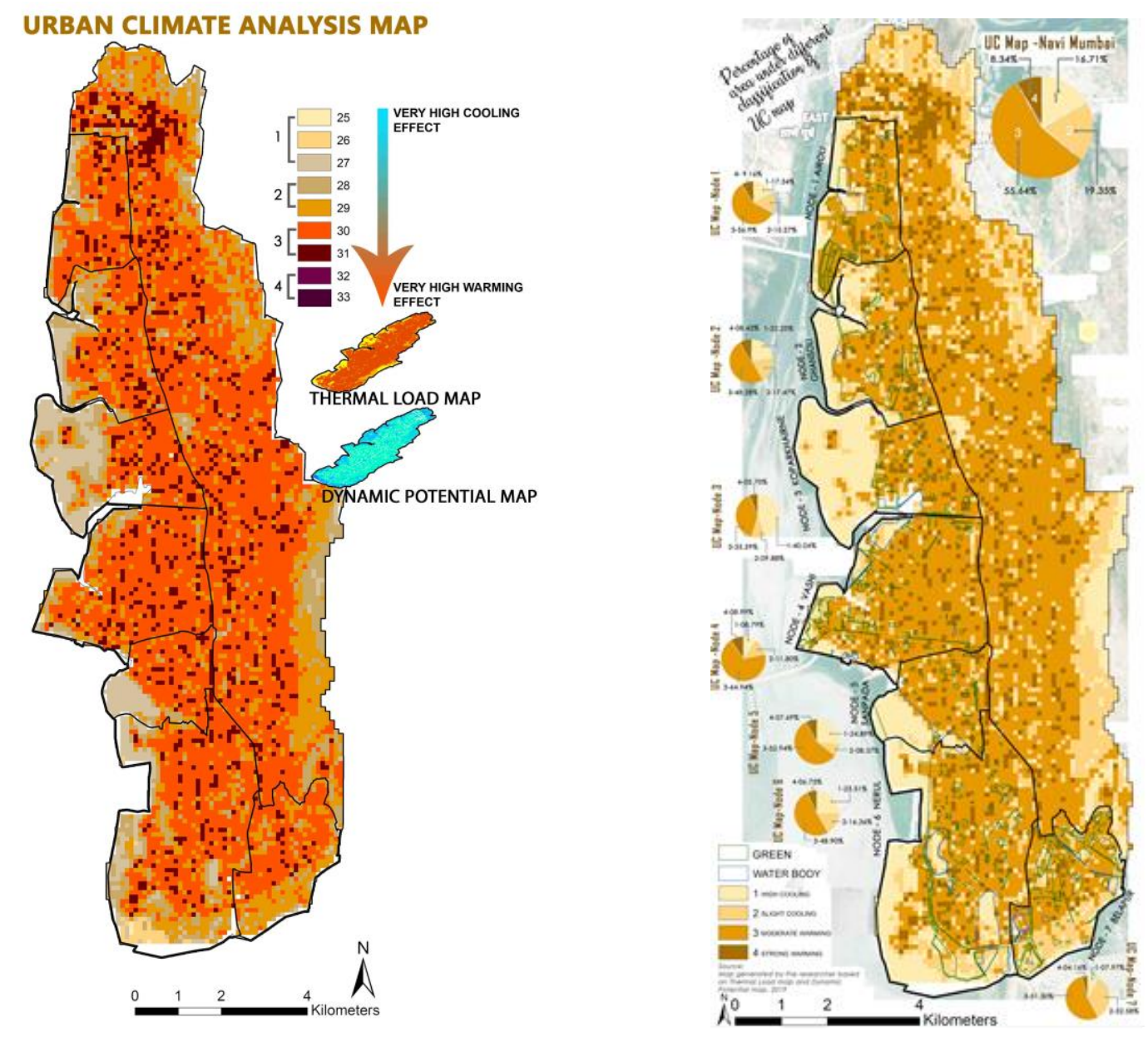

Figure 3 (left) Urban Climate Analysis Map and (right) Final Urban Climate Analysis Map for Navi Mumbai, 2018

Source: Map generated by the researcher based on Thermal Load map and Dynamic Potential map, 2019

It can be seen from the Urban Climate analysis map shown in Figure 3, which in the entire city, there are small patches of dark brown pixels which experiences a higher temperature due to the land use in those areas. At the same time areas near to green and blue infrastructure of the city are comparatively cooler. Thus, through planning decisions, we can incorporate these effective spaces into the core city area which can help in creating a comfortable built environment to sustain. Through the climate analysis map, the bottleneck areas can be identified clearly and the influential parameters pertaining to the same can be understood. This can help in taking planning decisions to make those areas more liveable with respect to the minimizing the effect of higher heat load in the areas. The climate map indicates the status of urban climate environment and the probable issues seen under it. It clarifies the challenges for spatial planning. This map can further give a clarification on how urban climate map is affecting other systems in the city. 


\section{Planning Tools and Techniques}

\subsection{Climate Analysis Tool}

ArcGIS software was used as a tool to process data acquired from Landsat 8 imagery of USGS portal, as it is the best tool that can turn datasets into useful information. ArcGIS helped in generating computer-based mapping and analysis which could make significant contributions in the areas of geographic planning and environmental science. Specifically, with respect to the green and blue infrastructure and the climatic parameters were integrated with ArcGIS to develop Urban Climate map for the study area.

\subsection{Statistical Techniques}

Statistical techniques like correlation, regressions, ranking and weighted sum were also used to establish the linkages between various control parameters which decide the dynamic urban climatic environment of the study area.

\subsection{Simulation Tool}

In order to analyze the climatic environment of the study area, grassroots level administrative boundary has been considered for further detailed investigation i.e, Node; Node- 4 was selected based on the fact that it has the least dynamic potential of the study region. A simulation was done to understand the outdoor thermal comforts. To perform the simulation, a 3-D model of the node was drafted with specifications of building height, type of land cover and type of plantation. This was integrated with the climatic parameter experienced in the node which includes temperature, relative humidity and prevailing wind. The simulation model helped in identifying the hot spots in the node which included roads and market area of the node. Thereby, planning interventions were made by improving and adding the Green and Blue infrastructure in the node.

\section{Results and Discussion}

\subsection{Grassroot Level Urban Climate Analysis}

The parameters for thermal and dynamic potential of each node were analyzed to understand the Urban Climate experienced in each node. It is clearly evident from Table -2 that out of all the nodes, Node - 3, i.e, Koparkhairne has less percentage of thermal load but due to the more percentage share of dynamic potential in the area, it is able to bring down the temperature of the area as a result, 40 per cent of the area lies under " 1 " in UC Analysis map which represents a lower temperature region. Node 2,6,7,5 and 1 which are Ghansoli, Nerul, Belapur, Sanpada and Airoli respectively, lies from Lower to moderate to high temperature region because of the distribution of the thermal load and dynamic potential of the area. In these areas the cumulative sum of lower and moderate temperature is almost 50 per cent of the total area. Out of all the nodes, Node- i.e, Vashi experiences a higher thermal load and at the same time the dynamic potential does not have a strong impact to counter the heat ingress due to thermal load. 
Table 1 Comparative analysis of thermal load and dynamic potential for all the nodes

\begin{tabular}{|c|c|c|c|c|c|c|c|c|c|c|c|c|c|c|c|}
\hline \multirow[t]{2}{*}{ S.No } & \multirow[t]{2}{*}{ NODES } & \multicolumn{5}{|c|}{ THERMAL LOAD } & \multicolumn{5}{|c|}{ DYNAMIC POTENTIAL } & \multicolumn{4}{|c|}{ UC MAP VALUES } \\
\hline & & 13 & 14 & 15 & 16 & 17 & 9 & 12 & 13 & 14 & 15 & 1 & 2 & 3 & 4 \\
\hline 1 & AIROLI & 0 & $3 \%$ & $5 \%$ & $92 \%$ & 0 & 0 & $0.74 \%$ & $26.91 \%$ & $61.19 \%$ & $9.42 \%$ & $17.34 \%$ & $15.27 \%$ & $56.90 \%$ & $9.16 \%$ \\
\hline 2 & GHANSOLI & 0 & $3 \%$ & $6 \%$ & $90.90 \%$ & $0.10 \%$ & $0.00 \%$ & $0.29 \%$ & $32.72 \%$ & $55.20 \%$ & $9.02 \%$ & $22.25 \%$ & $17.47 \%$ & $48.28 \%$ & $8.42 \%$ \\
\hline 3 & KOPAR KHAIRNE & 0 & $40 \%$ & $5 \%$ & $55 \%$ & 0 & $0.13 \%$ & $0.22 \%$ & $45.61 \%$ & $38.90 \%$ & $6.59 \%$ & $40.04 \%$ & $9.88 \%$ & $35.59 \%$ & $5.70 \%$ \\
\hline 4 & VASHI & 0 & $1 \%$ & $5 \%$ & $94 \%$ & 0 & $0.003 \%$ & $0.73 \%$ & $14.59 \%$ & $70.43 \%$ & $9.19 \%$ & $8.79 \%$ & $11.80 \%$ & $64.94 \%$ & $8.99 \%$ \\
\hline 5 & SANPADA & 0 & $20 \%$ & $1 \%$ & $79 \%$ & 0 & $0.002 \%$ & $0.45 \%$ & $31.67 \%$ & $55.43 \%$ & $8.37 \%$ & $24.89 \%$ & $8.37 \%$ & $52.94 \%$ & $7.69 \%$ \\
\hline 6 & NERUL & $1 \%$ & $2 \%$ & $11 \%$ & $86 \%$ & 0 & $0.20 \%$ & $4.16 \%$ & $25.65 \%$ & $59.48 \%$ & $6.94 \%$ & $23.51 \%$ & $16.36 \%$ & $48.90 \%$ & $6.75 \%$ \\
\hline 7 & BELAPUR & 0 & $1 \%$ & $2 \%$ & $97 \%$ & 0 & $0.00 \%$ & $4.35 \%$ & $35.35 \%$ & $53.55 \%$ & $4.16 \%$ & $7.97 \%$ & $32.58 \%$ & $51.30 \%$ & $4.16 \%$ \\
\hline \multicolumn{4}{|c|}{ Thermal Load Nomenclature - } & & & & \multicolumn{4}{|c|}{ Dynamic Potential Nomenclature - } & & \multicolumn{4}{|c|}{ UC Map Nomenclature - } \\
\hline \multicolumn{3}{|c|}{ 13- Very Low Thermal Load } & & & & & \multicolumn{4}{|c|}{ 9- Very High Dynamic Potential } & & \multicolumn{4}{|c|}{ 1- Very Low Temperture } \\
\hline \multicolumn{3}{|c|}{ 14- Low Thermal Load } & & & & & \multicolumn{4}{|c|}{ 12- High Dynamic Potential } & & \multicolumn{4}{|c|}{ 2- Low Temperture } \\
\hline \multicolumn{3}{|c|}{ 15- Moderate thermal load } & & & & & \multicolumn{4}{|c|}{ 13- Moderate Dynamic Potential } & & \multicolumn{4}{|c|}{ 3- Moderate Temperture } \\
\hline \multicolumn{3}{|c|}{ 16- High Thermal Load } & & & & & \multicolumn{4}{|c|}{ 14- Low Dynamic Potential } & & \multicolumn{4}{|c|}{ 4- High Temperture } \\
\hline \multicolumn{3}{|c|}{ 17- Very High Thermal Load } & & & & & \multicolumn{4}{|c|}{ 15- Very Low Dynamic Potential } & & & & & \\
\hline
\end{tabular}

Source: Compiled by the researcher based on node wise analysis of UC Map, 2019

\subsection{Observations and Findings}

For each node, thermal map, dynamic potential map and their respective urban climate map was generated. It is observed that the nodes experience a strong thermal load in the built up area, but, at the same time, within the built-up spaces, where the green and blue infrastructure are present, a considerably lower temperature is observed. A very strong cooling factor can be seen in the system which can convert the higher temperature areas to lower or moderate temperature zones thereby, establishing a major share of lower and moderate temperature in the system. Therefore, the areas with stronger dynamic potential are able to influence the thermal load of the system resulting to lower temperature in their respective area. When climate Analysis map is integrated with land use map, the results of climate analysis map gets well synchronized with specific land use allocations of the study area. Further, the cooling intensity of the study area lies under the green and blue spaces designated land uses in the system. Therefore, the node wise study results reflect the real system of the study area.

The map produced by overlaying the boundaries of urban green and blue infrastructure with urban climatic map clearly shows that most of the areas with green and blue infrastructure, experiences a lower temperature (subjected to the characteristic of the Green and Blue infrastructure) thereby, highlighting the potential of green and blue infrastructure to enhance the cooling effect in the system. It is evident that the areas with denser green and blue infrastructure experiences lower temperature compared to other areas.

\section{Recommendation and Conclusion}

\subsection{Planning Intervention and Policy Guidelines}

Navi Mumbai is regarded as one of the modern and planned cities of India and hence it has been designed to efficiently manage the urban challenges (CRISIL, 2012). However, various influence of the increased urbanization has altered the climatic condition of the city over the years. It is observed that areas with green and blue infrastructure experience a low thermal stress and high dynamic potential. Therefore, the planning intervention focuses on promoting Green and Blue infrastructure throughout the study area. An urban green and blue infrastructure network is made up of many elements that together facilitate movement through the city landscape. It is estimated that for every $100 \mathrm{~m}^{2}$ of vegetation added to a 
park, it can affect $1^{\circ} \mathrm{C}$ decrease in air temperature. Shashua-Bar and Hoffman (2000) investigated that the green space effect contributes to about $0.5^{\circ} \mathrm{C}$ cooling of the air temperature comparing to the shading effect. The analysis of the study area typically indicates key points for physical linkages, where an important connection exists or where connection has to be established. Therefore, the researchers have made an attempt to connect the various green and blue infrastructures in the study area to create a flow of benefits obtained from the services rendered from the GBI in the system. This study, thereby, suggests sector wise measures for a climate responsive planning for the city by exploring the optimal planning intervention, which can help to enhance GBI in the system. Based on the findings of this research study, researchers identified four strategic planning interventions as presented in the sequel and recommended to enhance cooling intensity and to promote sustainable built environment of the study region.

\section{(i) PROTECTIVE}

- Location of mangroves and ponds in the study area and taking protective measures to sustain the benefits of the resources in the system.

- $\quad$ Prohibition of dumping debris into mangroves and ponds.

- Declare Mangroves area as protected zone.

\section{(ii) DEFENSIVE}

- Planting saplings in the areas which has lost the mangrove cover due to encroachment.

- $\quad$ Fencing the new mangrove sapling from high tide.

- Dense Plantation of green cover in the open land separating each nodes.

\section{(iii) OFFENSIVE}

- Installing vertical mesh across the cross section of storm water drain to prevent leaves falling into the drains to be disposed off to the creek.

- $\quad$ Collecting the leaves fallen on the surface and making green manure for plants

- $\quad$ Planting trees such as water willow along the drain to increase the green cover in the study area.

\section{(iv) OPPORTUNISTIC}

- $\quad$ Planting tree saplings in the vacant land.

- $\quad$ Parking spaces to be covered with a slab where rooftop vegetation can be installed to keep the area cooler at the same time provide shad to the vehicles.

- Rooftop plantation over the railway station.

- Extensive plantation along the sides of the expressway running through the city.

- $\quad$ Skywalks to be developed into a public arena with vegetation and water body for both improving the GBI in the system as well as creating social spots in the city.

\section{(v) RESILIENCE}

- $\quad$ Compulsory Rooftop plantation for any new construction.

- $\quad$ Plantation along either side of the highway.

- Rooftop plantation over railway stations, skywalks and parking lots. 


\section{(vi) POST PROCESSING}

- $\quad$ Research on the climate resilience of the system through simulations with the existing and proposed measures for the improvement of the system.

- $\quad$ Developing the most viable economic measures for resilience in the system.

- $\quad$ Result analysis and display to the public at large.

\subsection{Application of Planning Intervention in Node: 4- 'Vashi'}

Vashi (Node - 4) was the first node developed by the planning authority of Navi Mumbai, as a result it is one of the most saturated nodes of the study area. Moreover, the dynamic potential of Vashi is less compared to the other nodes of the study area. Therefore, it has been considered for a detailed implication of the planning mechanism. Figure 4 identifies the protective, offensive, defensive and opportunistic area of the node. The existing Green and blue infrastructure have a total area of $1.6 \mathrm{Km}^{2}$. The proposed area for green and blue infrastructure development is $1.4 \mathrm{Km}^{2}$. Thereby, increasing the existing total green infrastructure to $3 \mathrm{Km}^{2}$ which will provide a stronger dynamic potential of the area.
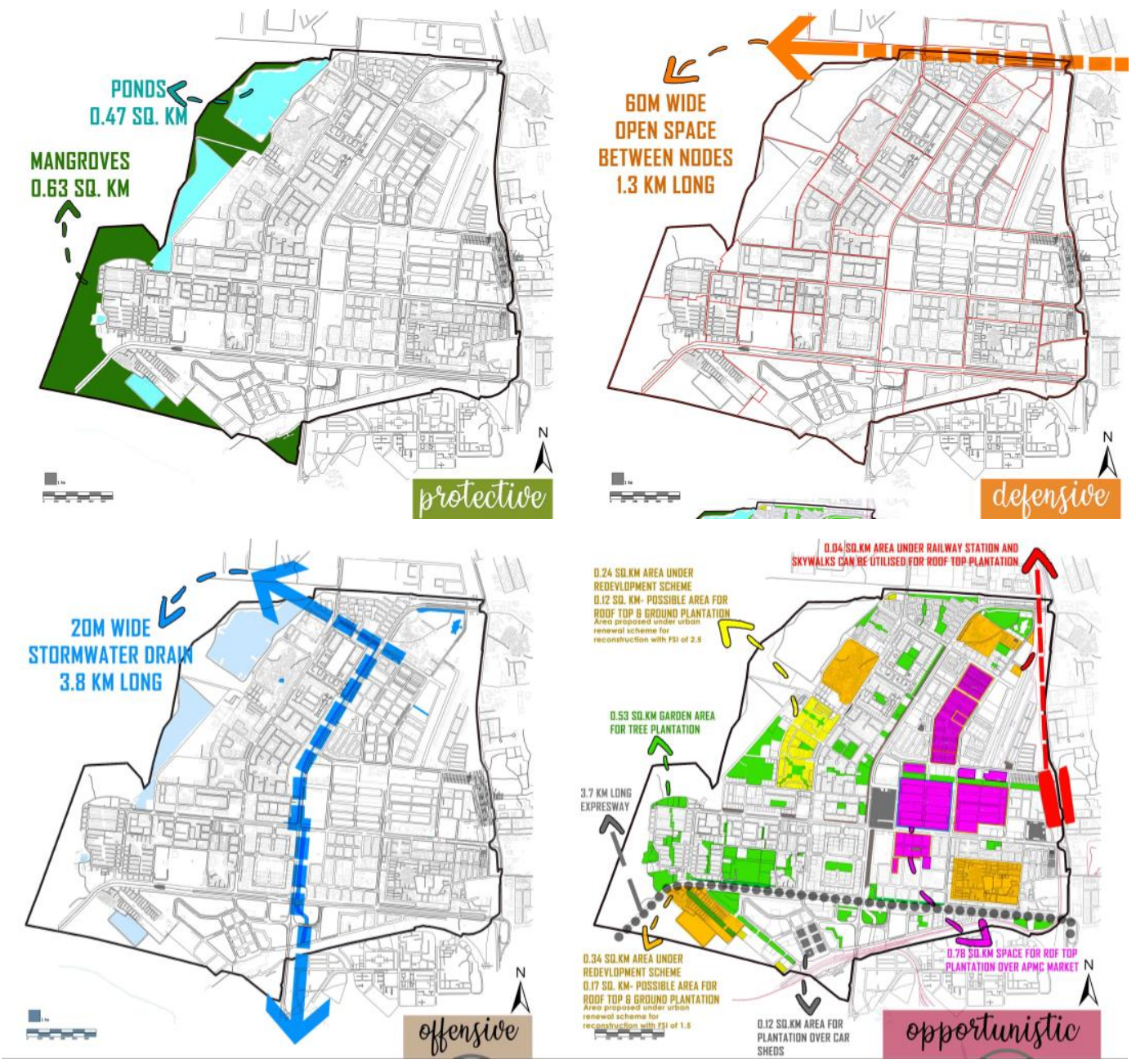

Figure 4 Planning interventions for Node -4

Source: Generated by the Researcher, 2019 
The planning interventions were made by improving and adding the Green and Blue infrastructure in the selected node of the study region. The results with intervention showed a dip in temperature by $2^{\circ} \mathrm{C}$ for the entire node as shown in Figure 6.

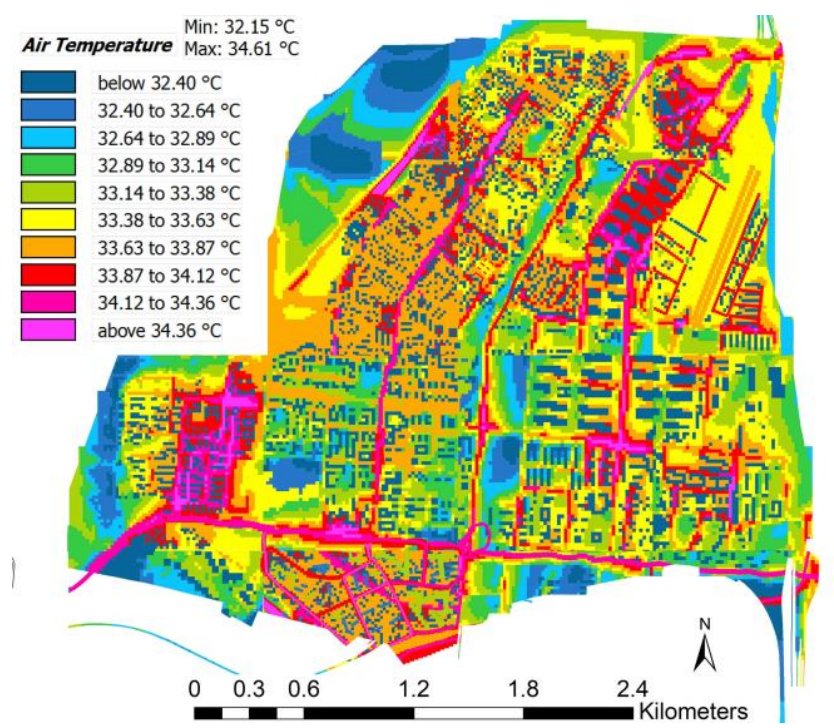

Figure 5 Existing temperature of the node without interventions

Source: Map generated by Researcher based on temperature, relative humidity, prevailing wind, green and blue spaces and building height of the selected node for 9th May 2019 using ENVI-met.

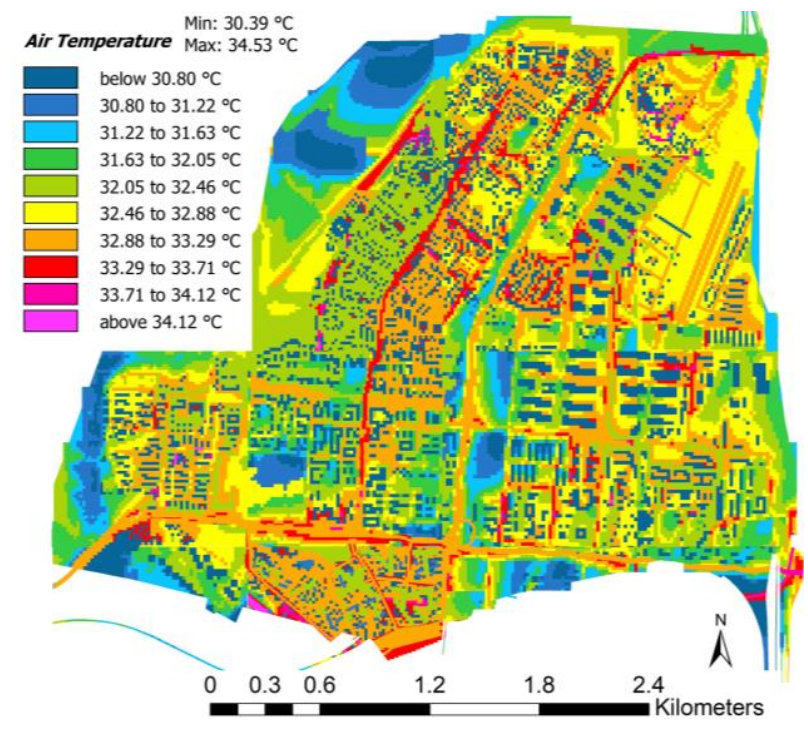

Figure 6 Temperature Difference experienced in the node after interventions

Source: Proposal Map generated by Researcher based on temperature, relative humidity, prevailing wind, green and blue spaces and building height of the selected node for 9th May 2019 (2:00 pm) using ENVI-met.

This research study conclude with the intervention includes $30 \mathrm{M}$ plantation on the nodal boundary, $4 \mathrm{M}$ wide plantation on both the des of the drainage network flowing in the node, $0.78 \mathrm{KM} 2$ rooftop plantations over APMC market. $3 \mathrm{M}$ wide plantation around the periphery of existing gardens, $0.04 \mathrm{KM}^{2}$ rooftop plantation across the railway station, $0.02 \mathrm{KM}^{2}$ 
plantation on the sides of the expressway, $0.12 \mathrm{KM}^{2}$ rooftop plantation over parking spaces, preserving and protecting the existing mangrove cover and water body and $0.30 \mathrm{KM}^{2}$ rooftop plantation over proposed redevelopment area. These planning interventions have facilitated in reducing the temperature of the node by $2^{\circ} \mathrm{C}$ in the study region. The results of this research study witnessed that Green and Blue infrastructure plays a vital role in regulating thermal comfort and therefore, it is recommended to have city planners/policy makers to focus on optimal planning interventions, which will pave the way to achieve sustainable living environment in the transforming urban system.

\section{References}

Ar. Ebin Horrison (2011) Urban Climate mapping for supporting urban planning in Chennai. International forum of Urbanism. 6. Singapore. Common Ground Publishing.

ARUP. (2006). Urban Climatic Map and Standards for Wind Environment. Hong Kong: CUHK.

CRISIL. (2012). Internal Review Document- Impact Assessment Study. Navi Mumbai: NMMC.

Di Luca, A. (2015). Effects of city expansion on heat stress under climate change conditions. PloS one, 10(2), e0117066. doi:10.1371/journal.pone.0117066

Früh, M. Ž.-A. (2016). Modelling the potential of green and blue infrastructure to reduce urban heat load in the city of Vienna. Climatic Change, 14.

GEDiKLi, B. (2018). Approaches to Climate Change In Spatial Planning And Design: International And Turkish Experiences.

K.R. Gunawardena, M. W. (2016). Utilising green and bluespace to mitigate urban heat island intensity. Elsevier, 16.

L. Shashua-Bar, M.E. Hoffman (2000) "Vegetation as a climatic component in the design of an urban street - An empirical model for predicting the cooling effect of urban green areas with trees, Elesevier, Energy and Buildings 31 (2000) 221-235, (May).

Roser, H. R. (2018, September). Urbanization. Retrieved from Our World in Data: https://ourworldindata.org/urbanization

UN Habitat. (2016). World Cities Report 2016 - Urbanization and development. Kenya: UN Habitat. 